\title{
Cardiopulmonary Safety of Propofol Versus Midazolam/Meperidine Sedation for Colonoscopy: A Prospective, Randomized, Double-Blinded Study
}

\author{
Bunyamin Gurbulak ${ }^{1}$; Sinan Uzman ${ }^{2, *}$; Esin Kabul Gurbulak ${ }^{3}$; Yasar Gokhan Gul ${ }^{4}$; Mehmet \\ Toptas $^{2}$; Sevim Baltali ${ }^{4}$; Osman Anil Savas ${ }^{5}$ \\ ${ }^{1}$ Department of General Surgery, Arnavutkoy State Hospital, Istanbul, Turkey \\ ${ }_{3}^{2}$ Department of Anesthesiology and Reanimation, Haseki Training and Research Hospital, Istanbul, Turkey \\ ${ }^{3}$ Department of General Surgery, Sisli Etfal Training and Research Hospital, Istanbul, Turkey \\ ${ }^{4}$ Department of Anesthesiology and Reanimation, Arnavutkoy State Hospital, Istanbul, Turkey \\ 5 Department of General Surgery, Haseki Training and Research Hospital, Istanbul, Turkey \\ ${ }^{*}$ Corresponding Author: Sinan Uzman, Department of Anesthesiology and Reanimation, Haseki Training and Research Hospital, Istanbul, Turkey. Tel: +90-5055645271, Fax: +90- \\ 2125294453, E-mail: drsinanuzman@yahoo.com
}

Received: April 8, 2014; Revised: August 6, 2014; Accepted: September 1, 2014

\begin{abstract}
Background: Different levels of pharmacological sedation ranging from minimal to general anesthesia are often used to increase patient tolerance for a successful colonoscopy. However, sedation increases the risk of respiratory depression and cardiovascular complications during colonoscopy.

Objectives: We aimed to compare the propofol and midazolam/meperidine sedation methods for colonoscopy procedures with respect to cardiopulmonary safety, procedure-related times, and patient satisfaction.

Patients and Methods: This was a prospective, randomized, double-blinded study, in which 124 consecutive patients undergoing elective outpatient diagnostic colonoscopies were divided into propofol and midazolam/meperidine sedation groups(n:62, $\mathrm{m} / \mathrm{f}$ ratio:26/36, mean age: $46 \pm 15$ for the propofol group; $\mathrm{n}: 62$, m/f ratio:28/34, mean age: $49 \pm 15$ for the midazolam/meperidine group) by computer-generated randomization. The frequency of cardiopulmonary events (hypotension, bradycardia, hypoxemia), procedure-related times (duration of colonoscopy, time to cecal intubation, time to ileal intubation, awakening time, and time to hospital discharge) and patients' evaluation results (pain assessment, quality of sedation, and recollection of procedure) were compared between the groups.

Results:There were no statistically significant differences between the two groups with respect to demographic and clinical characteristics of the patients, the frequency of hypotension, hypoxemia or bradycardia, cecal and ileal intubation times, and the duration of colonoscopy. The logistic regression analysis indicated that the development of cardiopulmonary events was not associated with the sedative agent used or the characteristics of the patients. The time required for the patient to be fully awake and the time to hospital discharge was significantly longer in the propofol group (11 \pm 8 and $37 \pm 11$ minutes, respectively) than the midazolam/meperidine group ( $8 \pm 6$ and $29 \pm$ 12 minutes, respectively $)(\mathrm{P}=0.009$ and $\mathrm{P}<0.001$, respectively).The patient satisfaction rates were not significantly different between the groups; however, patients in the propofol group experienced more pain than patients in the midazolam/meperidine group (VAS score: $0.31 \pm 0.76$ vs. $0 \pm 0 ; \mathrm{P}=0.002$ ).

Conclusions: Midazolam/meperidine and propofol sedation for colonoscopy have similar cardiopulmonary safety profiles and patient satisfaction levels. Midazolam/meperidine can be preferred to propofol sedation due to a shorter hospital length of stay and better analgesic activity.
\end{abstract}

Keywords:Colonoscopy; Propofol; Midazolam; Randomized Controlled Trial

\section{Background}

Colonoscopy is an essential screening, diagnostic, therapeutic and follow-up tool for colorectal diseases (1-4). A throughout colonoscopy with complete cecal intubation is required for a successful procedure. The complete intubation, however, can be interfered by reasons including technical issues, poor patient tolerance and/or poor bowel preparation $(5,6)$. Among these, patient comfort is accepted as the most important factor for a successful colonoscopy; however, most patients cannot tolerate the discomfort and pain caused by this invasive endoscopic procedure
(1-5). Different levels of pharmacological sedation ranging from minimal to general anesthesia are therefore generally used in colonoscopy to increase patient tolerance $(3,5)$. Midazolam is a benzodiazepine and a powerful amnesic, anxiolytic and sedative agent with a short elimination halflife (7-9). During colonoscopy, midazolam induces moderate sedation where the patient attains a decreased level of consciousness and response to verbal or tactile stimulation is preserved $(2,9,10)$. The combination of midazolam with opioids provides the best procedural sedation during colo-

Copyright (C) 2014, Iranian Red Crescent Medical Journal. This is an open-access article distributed under the terms of the Creative Commons Attribution-NonCommercial 4.0 International License (http://creativecommons.org/licenses/by-nc/4.0/) which permits copy and redistribute the material just in noncommercial usages, provided the original work is properly cited. 
noscopy, along with adequate spontaneous ventilation (2, $3,8,9)$. The midazolam/meperidine combination can be used to achieve better results in sedation, but with a risk of prolonged recovery and delayed hospital discharge due to the longer action duration of meperidine $(2,3,10,11)$.

Propofol (2, 6-diisopropyl phenol) is a short acting anesthetic agent, providing a considerably rapid onset of sedation and shorter recovery time with less nausea and vomiting $(1,2,8,10,12)$. The sedation achieved by propofol is dose-dependent; high doses of propofol may easily induce deep sedation or even general anesthesia $(10,12,13)$. When used as a single sedative agent during colonoscopy, administration of more propofol is necessary to prevent patient movements, especially those due to pain and coughing that can interfere with the procedure (10).

It is important to evaluate the risk factors of different sedative agents used in colonoscopy with respect to the development of CP complications and the duration of the procedure. Numerous studies have compared propofol and midazolam/meperidine combination with regard to their efficacies, recovery times, side effects, and patient satisfaction rates $(1,3,7,14)$.

\section{Objectives}

The main objective of this prospective, randomized, double-blinded study was to compare the propofol and midazolam/meperidine sedation levels during colonoscopy with respect to the incidence of cardiopulmonary events (CPE) and to evaluate the effect of risk factors on development of CP complications. The procedure-related times and patient satisfaction rates in these two sedation approaches were also compared.

\section{Patients and Methods}

\subsection{Study Design and Population}

Two different sedation protocols, applied between February 2014 and March 2014, were compared in this prospective, randomized, double-blinded study, conducted in the Endoscopy Center of the Arnavutkoy State Hospital, a referral hospital with 210 beds in Istanbul, Turkey. The study protocol was approved by the Local Hospital Ethics Committee, conducted according to the Declaration of Helsinki, and all the patients provided written informed consents (date/protocol number of ethical approval: 2.5.2014/114).

The patients enrolled in the study were selected from 141 consecutive patients who were referred for an elective outpatient diagnostic colonoscopy (Figure 1). Patients who were younger than 18 years of age, pregnant or breast-feeding, intolerant or allergic to propofol or midazolam and meperidine, egg and soybean oil, had an American Society of Anesthesiologists (ASA) physical classification status higher than III, history of obstructive sleep apnea syndrome, a higher risk of difficult intubation (short-thick neck, inability to widely open the mouth, Mallampati class III-IV), history of complications in previous sedations, and poor bowel cleansing were excluded from the study. Patients were divided into two groups by computer-generated randomization: Group P received sedation with propofol and Group MM received sedation with midazolam/meperidine.

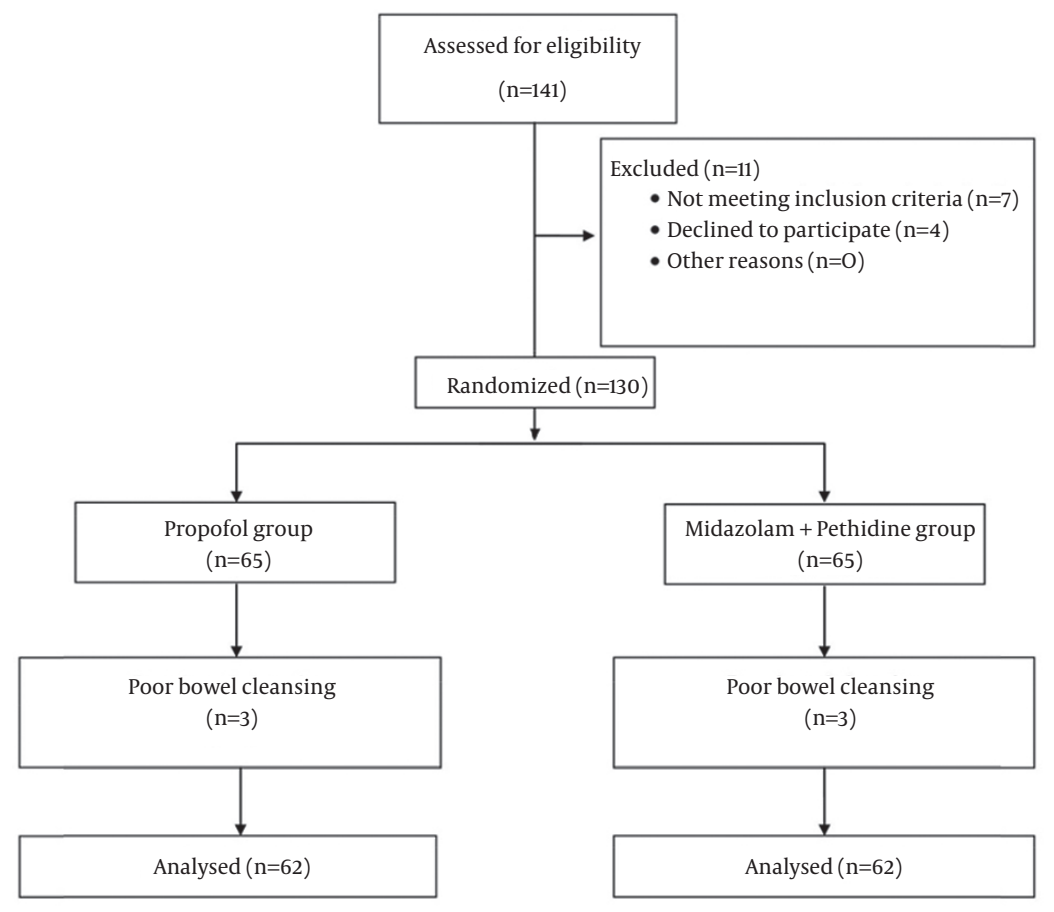


GurbulakB et al.

\subsection{Endoscopy Procedure}

All colonoscopy procedures were performed by the same general surgeon with more than five years of experience in gastrointestinal tract endoscopy who was blinded to the sedative agents. Sedations were administered by the same anesthesiologist. The patients as well as the endoscopy and recovery room nurses were also blinded to the sedative agents.

In the endoscopy room, all the patients received intravenous isotonic saline at $10 \mathrm{~mL} / \mathrm{kg} / \mathrm{h}$ and $3 \mathrm{~L} / \mathrm{min}$ oxygen by a nasal cannula. They also received $1.5 \mathrm{mg}$ midazolam (Dormicum, Roche, Istanbul, Turkey) and $50 \mu \mathrm{g}$ fentanyl (Fentanyl Citrate, Meditera, Izmir, Turkey) before the induction of sedation. In group P, sedation was started with an initial $1 \mathrm{mg} / \mathrm{kg}$ bolus of propofol (propofol 2\%, Fresenius Kabi, Istanbul, Turkey) administered intravenously, followed by titration with 10-20 mg doses as needed for continuous sedation. Patients in the MM group received intravenous injections of $0.05 \mathrm{mg} / \mathrm{kg}$ midazolam and $0.4 \mathrm{mg} / \mathrm{kg}$ meperidine (Aldolan, Liba Lab, Istanbul, Turkey) as the initial bolus; this was then titrated with 1-2 mg midazolam and 5-10 mg meperidine as needed for continuous sedation. The required dose per kilogram was calculated by ideal body weight $(50+2.3 \mathrm{~kg}$ per inch over five feet for men and $45.5+2.3 \mathrm{~kg}$ per inch over five feet for women) (15). The level of sedation was assessed with Observer's Assessment of Alertness/Sedation (OAA/S) score ( 1 = fully sedated, 5 = not sedated) (16), every five minutes after the initial bolus injection of the drugs to preserve the desired level of sedation. All the equipment required for resuscitation, as well as flumazenil (Anexate, Deva, Istanbul, Turkey), naloxane (Abbott, Istanbul, Turkey), the antagonists of midazolam and opioid, were present in the endoscopy room.

\subsection{Evaluation of Cardiopulmonary Safety}

Electrocardiography, noninvasive blood pressure (NIBP), heart rate (HR), respiratory rate (RR) and peripheral oxygen saturation $\left(\mathrm{SpO}_{2}\right)$ of all the patients were monitored (Drager Infinity Delta, Drager Medical Systems Inc., Danvers, MA, USA), starting from the induction of sedation until discharge from the hospital. All monitoring parameters, procedure-related times (duration of colonoscopy (total procedure time), time to cecal intubation, time to ileal intubation, awake time (time for the patient to have OAA/S score of 5 in the recovery room), and time to hospital discharge after colonoscopy procedure), CPE, as well as age, gender, body mass index, ASA, alcohol or tobacco consumption, co-existing diseases, history of medical treatments and history of previous surgical operations were recorded by the same research resident who was blinded to the grouping.

Blood pressure was measured automatically every five minutes and HR, RR, and SpO2 were assessed continuously. CP complications were classified as follows:1) hypotension ( $>30 \%$ decrease in baseline mean arterial pressure (MAP) or systolic arterial pressure (SAP) $<90 \mathrm{mmHg}$ ), 2) bradycar- dia (heart rate $<50$ beats/minute), 3) hypoxemia $\left(\mathrm{SpO}_{2}<\right.$ $90 \%$ with supplemental oxygen), 4) apnea (absence of respiration for more than 15 seconds), 5) others: dysrhythmia, ST changes, chest pain, pulmonary edema, 6) permanent damage or death. Patients with hypotension were treated with $250 \mathrm{~mL}$ isotonic saline, infused in a five-minute period. Five milligrams of ephedrine (ephedrine $\mathrm{HCl}$, Osel Ilac, Istanbul, Turkey) was administered intravenously to the patients who did not respond to saline treatment or when SAP decreased below $90 \mathrm{mmHg}$. Bradycardia was treated with intravenous administration of $0.5 \mathrm{mg}$ of atropine (atropine sulfate, Biofarma, Istanbul, Turkey). In patients with $\mathrm{SpO}_{2}<90 \%$ for more than 15 seconds, chin lift maneuver was performed. When chin lift maneuver treatment failed to increase the $\mathrm{SpO}_{2}$ level, the patient was treated with mechanical ventilation and flumazenil injection.

\subsection{Postprocedural Follow-up and Evaluation of Patient' Satisfaction}

The patients were transferred to the recovery room at the end of the procedure. A recovery room nurse, blinded to the patients' groups, evaluated the arterial blood pressure, $\mathrm{HR}, \mathrm{SpO}_{2}$ and consciousness level of patients. Patients without hypotension (MAP $<70 \mathrm{mmHg}$ ), bradycardia (heart rate $<60$ beats/minute) and hypoxemia $\left(\mathrm{SpO}_{2}<95 \%\right.$ breathing room air), and the ones who were able to sit on the bed without assistance and were fully awake (OAA/S score $=5)$, were allowed to be discharged from the hospital. Before their discharge, all the patients completed a satisfaction questionnaire which included pain assessment, quality of sedation and recollection of the procedure. The pain level during intubation was evaluated by a $10-\mathrm{cm}$ visual analog scale (VAS; $0=$ no pain, $10=$ severe pain). The quality of sedation was assessed by the patients as excellent, good, fair, or poor; the recollection of procedure was determined by yes or no.

\subsection{Statistical Analysis}

Statistical analysis was performed by the SPSS software package for Windows (Statistical Package for Social Sciences, version 17.0, SPSS Inc., Chicago, Illinois, USA). Quantitative variables were expressed as mean \pm standard deviation (SD), whereas categorical variables as number of patients and percentage. The normality of quantitative variables was analyzed by Kolmogorov-Smirnov test and the normally distributed variables were compared using student's t-test. Categorical variables were compared by chi-square or Fisher's exact test. Logistic regression analysis was performed to determine the independent risk factors for the development of cardiopulmonary side effects and HosmerLemeshow test was used to assess the goodness-of-fit of the model. Calculation of sample size was based on the incidence of CPE. Based on a previous study, the incidence of CPE (transient hypotension and oxygen desaturation) was approximately $29 \%$ with propofol sedation (17). Power analysis with $\alpha=0.05$ and $\beta=0.2$ for determining the $50 \%$ reduc- 
tion on CPE with midazolam and meperidine revealed that each group required a minimum of 61 patients. A P value $<$ 0.05 was considered as statistically significant.

\section{Results}

\subsection{Baseline Characteristics of Patients}

The study included 124 consecutive patients who underwent elective outpatient diagnostic colonoscopy. The patients were divided into two groups by computer generated randomization; group P: sedation with propofol ( $n=62$ ) and group MM: sedation with midazolam/meperidine ( $n=62$ ) (Figure 1$)$. Characteristics of the patients in the groups and doses of sedative agents administered during colonoscopy are summarized in Table 1 . There were no statistically significant differences between the two groups in terms of age, gender, body mass index, ASA, alcohol/tobacco usage, co-existing diseases, and history of medical treatments and surgical operations. In group $\mathrm{MM}$, although the differences were not significant, the numbers of patients with cardiovascular diseases $(\mathrm{n}=15$, $24 \%$ ) as well as the ones who had an abdominal surgery (n $=17,27 \%)$ were higher than group $\mathrm{P}(\mathrm{n}=12,20 \%$ and $\mathrm{n}=13$, $21 \%$, respectively) ( $\mathrm{P}>0.050$ for both).

\begin{tabular}{|c|c|c|c|}
\hline Characteristics & Group P & $\begin{array}{c}\text { Group } \\
\text { MM }\end{array}$ & P Value \\
\hline Age, y & $46(19-78)$ & $48(19-88)$ & 0.840 \\
\hline Gender & & & 0.717 \\
\hline Male & 26 & 28 & \\
\hline Female & 36 & 34 & \\
\hline BMI, $\mathrm{kg} / \mathrm{cm}^{2}$ & $27.6 \pm 5.4$ & $27.2 \pm 6.4$ & 0.660 \\
\hline ASA classification & & & 0.085 \\
\hline I & $45(72)$ & $33(54)$ & \\
\hline II & $14(23)$ & $25(41)$ & \\
\hline III & $3(5)$ & $4(5)$ & \\
\hline Tobacco/alcohol usage & $10(16)$ & $14(23)$ & 0.572 \\
\hline Co-existing disease & $23(37)$ & $30(48)$ & 0.204 \\
\hline Cardiovascular & $12(20)$ & $15(24)$ & \\
\hline Diabetes mellitus & $9(15)$ & $9(15)$ & \\
\hline Others & $12(52)$ & $14(23)$ & \\
\hline Medical treatment & $23(37)$ & $27(44)$ & 0.464 \\
\hline Cardiovascular drugs & 12 & 15 & \\
\hline Oral antidiabetics & 9 & 9 & \\
\hline Others & 16 & 13 & \\
\hline Operation history & & & 0.685 \\
\hline Abdominal & $13(21)$ & $17(27)$ & \\
\hline Others & $13(21)$ & $11(18)$ & \\
\hline \multicolumn{4}{|l|}{ Total dose, mg } \\
\hline Midazolam & 2.5 & $6.5 \pm 1.1$ & \\
\hline Fentanyl & 0.05 & 0.05 & \\
\hline Propofol & $118 \pm 32$ & - & \\
\hline Meperidine & - & $30.5 \pm 5.6$ & \\
\hline
\end{tabular}

\subsection{Cardiopulmonary Complications}

The incidence of CP complications was compared between the two groups and their results are summarized in Table 2. There were no colonoscopy-related apneas or deaths. The difference between group $\mathrm{P}$ and group MM with respect to the incidence of hypotension, hypoxemia, and bradycardia was not statistically significant. CPE, particularly hypotension, was observed more frequently in group P ( $n=26,42 \%$ for all the events and $n=22,35.5 \%$ for hypotension) than group $\mathrm{MM}(\mathrm{n}=20,32.3 \%$ and $\mathrm{n}=17$, $27.4 \%$, respectively) ( $P>0.05$ for both). Bradycardia was observed only in one patient in group $\mathrm{MM}(\mathrm{n}=1,1.6 \%, \mathrm{P}=$ 1.000). None of the patients had dysrhythmia, ST changes on ECG, chest pain, pulmonary edema, permanent brain damage, or death.

Table 2. Cardiopulmonary Complications and Procedure-Related Times $(n=62)^{a}$

\begin{tabular}{|c|c|c|c|}
\hline Variable & Group P & $\begin{array}{l}\text { Group } \\
\text { MM }\end{array}$ & P Value \\
\hline Adverse events & $26(42)$ & $20(32.3)$ & 0.265 \\
\hline Hypotension & $22(35.5)$ & $17(27.4)$ & 0.334 \\
\hline Hypoxemia & $5(8.1)$ & $4(6.5)$ & 0.729 \\
\hline Bradycardia & $0(0)$ & $1(1.6)$ & 1.000 \\
\hline \multicolumn{4}{|l|}{$\begin{array}{l}\text { Procedure-related times, } \\
\text { min }\end{array}$} \\
\hline Duration of colonoscopy & $22 \pm 8$ & $25 \pm 15$ & 0.111 \\
\hline Time to cecal intubation & $12 \pm 6$ & $13 \pm 8$ & 0.363 \\
\hline Time to ileal intubation & $10 \pm 7$ & $13 \pm 8$ & 0.099 \\
\hline Awake time & $11 \pm 8$ & $8 \pm 6$ & 0.009 \\
\hline $\begin{array}{l}\text { Time to hospital dis- } \\
\text { charge }\end{array}$ & $37 \pm 11$ & $29 \pm 12$ & $<0.001$ \\
\hline
\end{tabular}

\subsection{Procedure-Related Times}

The comparisons of propofol and midazolam/meperidine sedation on the duration of colonoscopy, cecal and ileal intubation times, awake time and time to hospital discharge are given in Table 2 . There was no statistically significant differences between the groups with respect to cecal and ileal intubation times and duration of colonoscopy, although the colonoscopy procedure was longer in group MM $(25 \pm 15$ minutes $)$ compared with group $\mathrm{P}(22 \pm 8$ minutes $)(\mathrm{P}=0.111)$. Statistically significant differences between the two groups were observed with respect to awake time and time to hospital discharge $(\mathrm{P}=0.009$ and $\mathrm{P}<0.001$, respectively). Accordingly, the time required to have an OAA/S score of 5 (fully awake) was significantly longer in group $\mathrm{P}(11 \pm 8$ minutes) than group MM ( $8 \pm 6$ minutes). Time to hospital discharge (the period after the colonoscopy procedure ended and the patient was transferred to the recovery room and then discharged) was also found to be significantly longer in group $\mathrm{P}$ ( $37 \pm 11$ minutes) compared to group MM (29 \pm 12 minutes). 


\subsection{Predictive Risk Factors For Cardiopulmonary Complications}

The risk factors for the development of CP complications were evaluated with logistic regression analysis (Table 3). The results indicated that the study group, age, gender, ASA classification, alcohol or tobacco use, and presence of concomitant diseases in the patients were not related to cardiopulmonary complications $(\mathrm{P}>0.050$ in all) (Table 4).

Table 3. Logistic Regression Analysis of Risk Factors for Cardiopulmonary Complications

\begin{tabular}{lcc}
\hline Variable & $\begin{array}{c}\text { Odds Ratio(95\% Confi- } \\
\text { dence Interval) }\end{array}$ & P Value \\
\hline Study group & $0.66(0.30-1.46)$ & 0.306 \\
Age & $0.99(0.96-1.03)$ & 0.657 \\
Gender & $1.54(0.69-3.47)$ & 0.292 \\
ASA classification & $0.38(0.11-1.26)$ & 0.114 \\
Tobacco/alcohol usage & $0.65(0.22-1.87)$ & 0.421 \\
Concomitant disease & $1.71(0.54-5.44)$ & 0.361 \\
\hline
\end{tabular}

Table 4. Patients' Satisfaction with Sedation $(n=62)$ a, b

\begin{tabular}{lccc}
\hline Variable & Group P & Group MM & P Value \\
\hline VAS, cm & $0.31 \pm 0.76$ & 0 & 0.002 \\
$\begin{array}{l}\text { Recollection of the proce- } \\
\text { dure }\end{array}$ & & & 1.000 \\
$\quad$ Yes & 0 & 0 & \\
$\quad$ No & 62 & 62 & \\
Quality of sedation & & & 0.445 \\
$\quad$ Excellent & $51(82)$ & $55(89)$ & \\
$\quad$ Good & $11(18)$ & $7(11)$ & \\
$\quad$ Fair & $0(0)$ & $0(0)$ & \\
\hline \multicolumn{1}{l}{ Poor } & $0(0)$ & $0(0)$ & \\
\hline
\end{tabular}

a Abbreviation: VAS, visual analog scale.

b Data are presented as Mean \pm SD or No. (\%).

\subsection{Patient Satisfaction}

None of the patients remembered the colonoscopy procedure $(\mathrm{P}=1.000)$. There was no statistically significant difference between the groups with respect to patient satisfaction and the majority of the patients in both groups ( $n=51,82 \%$ in group $P$ and $n=55,89 \%$ in group MM) described the procedure as excellent. The VAS score, on the other hand, indicated a statistically significant difference between the groups $(\mathrm{P}=0.002)$. Accordingly, none of the patients in group MM experienced pain (VAS $=0 \pm 0$ ), whereas for the patients in group $P$ the mean VAS score was $0.31 \pm 0.76$.

\section{Discussion}

Colonoscopy is an invasive tool for screening colorec- tal diseases and has higher complication rates due to common use of sedation to increase patient comfort (2, 18). Unexpected deaths during colonoscopy are often associated with cardiorespiratory failure, especially during sedation-induced sleep periods (19-21). The sedation strategy and the level of sedation should be based on risk evaluation (patient's age, comorbidities, anxiety) and characteristics of the endoscopic procedure (22).

Sedation during colonoscopy is usually achieved pharmacologically by benzodiazepines, either alone (mostly midazolam, $47 \%$ ) or in combination with an opiate $(1,2,8$, 9 ). Since the action of the drugs may last longer than the procedure, the most commonly encountered problems related to drug-induced sedation during colonoscopy are prolonged recovery with a delay in hospital discharge, increased costs, and disruption of daily activities of patients (2). The use of drug combinations and anesthesiological practices have been reported to increase the risk of oxygen desaturation and cardiorespiratory complications. Therefore, $\mathrm{CP}$ monitoring during colonoscopy is very important to decrease the complication-related morbidity $(1,5)$. A recent multicenter study on 18271 patients aged 40 years and over who underwent a colonoscopy for screening, surveillance or evaluation, reported that the most common complications were respiratory depression (0.75\%) and immediate cardiovascular complications (0.49\%), most commonly seen as hypotension or bradycardia (18).

There is an increasing use of propofol sedation during colonoscopy due to satisfaction of endoscopists and shorter recovery time for patients $(2,8,9)$. However, propofol increases the risk of sedation-related CPE due to its relatively narrow therapeutic range $(2,8)$. A prospective study of propofol-induced deep sedation on 1104 patients undergoing colonoscopy proved that hypotension and respiratory depression constituted the majority of complications (1). The authors concluded that although propofol-induced sedation provided an excellent pain control along with a short recovery time and no significant hemodynamic side effects when carefully titrated, all the patients required careful monitoring and care of an anesthesiologist (1). A complication rate of $0.6 \%$ (one duodenal perforation, one hypotension, one aspiration pneumonia and three apneas) was reported in a total of 1000 patients who underwent an endoscopic ultrasound procedure with propofol sedation (23). Cardin et al. (5) reported on 617 procedures performed under standard deep sedation induced by propofol, who had a $5 \%$ rate of adverse events relating to sedation, including episodes of apnea, hypo- or hypertension, hypoxemia or cardiac arrhythmia. In a very recent study on 40 patients evaluating the levels of sedation needed to undergo colonoscopy comfortably with propofol sedation, $96 \%$ of the patients reached the levels of deep sedation and $89 \%$ reached general anesthesia at risk for respiratory depression, airway obstruction and hemodynamic compromise (12).

Various sedation scales have been developed to describe 
the depth of sedation. In this study, OAA/S was used to assess the level of sedation (24). Liu et al. $(25,26)$ observed a good correlation between OAA/S scoring and BIS values during propofol and midazolam-induced sedation. Otherwise, OAA/S does not take into account the CP status, unlike the Ramsey sedation scale and the ASA definitions of levels of sedation. Therefore, CP status was assessed with ECG, blood pressure and $\mathrm{SpO}_{2}$ monitoring independently from sedation.

To compare the incidence of CPE and evaluate the effects of independent risk factors on development of CP complications during propofol (group P) and midazolam/meperidine (group MM) sedations, 141 consecutive patients undergoing elective outpatient diagnostic colonoscopy were investigated in this prospective, randomized, double-blinded study. There were no statistically significant differences between the randomly selected groups in terms of characteristics and medical and surgical histories of the patients. The results indicated no statistically significant differences between groups P and MM with respect to the incidence of cardiopulmonary events such as hypotension, hypoxemia and bradycardia. Although insignificant, the incidence of hypotension was more frequent in group $\mathrm{P}(\mathrm{n}=22,35.5 \%)$ than group MM $(\mathrm{n}=$ $17,24.7 \%$ ). The number of patients with co-existing cardiovascular diseases were higher in group MM $(n=15,24 \%)$ than group $\mathrm{P}(\mathrm{n}=12,20 \%)$, whereas the incidence of CPE was higher in group $\mathrm{P}(\mathrm{n}=26,42 \%)$ compared with group MM ( $n=20,32.3 \%)$. There are previous studies reporting no differences between propofol and midazolam/meperidine sedation with respect to incidence of CPE, similar to the findings of this study. On the other hand, some others have reported better results with propofol sedation. For example, in a prospective randomized study comparing propofol and midazolam/meperidine for advanced upper endoscopies, Vargo et al. (27) reported no differences between the groups with respect to the incidence of oxygen desaturation, apnea, hypotension or bradycardia. In another prospective randomized study, five CP complications were reported among 80 patients; with only one in the propofol group (oxygen desaturation during an episode of epistaxis) and the other four in the midazolam/ meperidine groups (one hypotension and bradycardia, two hypotension and one tachycardia) (7). In a recent meta-analysis of randomized controlled trials comparing traditional sedation approaches with propofol sedation, there were no significant differences between the groups with respect to cardiopulmonary complications (i.e. hypoxia, hypotension, arrhythmia, and apnea) (28). On the other hand, in their meta-analysis of the current literature, Qadeer et al. (29) concluded that the incidence of cardiopulmonary complications in propofol sedation was lower than that of traditional agents like midazolam.

The comparison of procedure-related times between propofol and midazolam/meperidine sedations during colonoscopy indicated that the awake time and time to hospital discharge were significantly shorter in group
MM compared with group P. These results were in contradiction to the results in the literature; studies found that midazolam/meperidine sedation was usually associated with prolonged recovery and delay in hospital discharge $(2,3,10,11)$, whereas propofol sedation was mostly used for its rapid onset of sedation and shorter recovery time $(1,2,8,10,12)$. The sedation level achieved by propofol is dose-dependent and higher doses of propofol are usually administered when it is used as a single sedative agent, which may explain the delay in awakening and hospital discharge times observed in this study $(10,12,13)$.

There are a number of reports on higher patient comfort and satisfaction rates achieved with propofol compared to traditional sedation approaches including the midazolam and meperidine combination (7, 8, 26, 30). However, a recent study analyzing 17027 colonoscopies performed mostly by the combination of midazolam and an opiate (either pethidine or fentanyl) indicated that successful colonoscopies without significant discomfort in majority of patients did not necessarily require deep sedations (6). Similarly, in this study we observed no statistically significant differences between the groups with respect to patient satisfaction and most of the patients described the procedure as excellent. Interestingly, the VAS score was significantly higher in group $\mathrm{P}(0.31 \pm 0.76)$ compared with group MM (VAS $=0 \pm 0)(P=0.002)$, indicating the patient's perception of pain during colonoscopy when sedated with propofol.

The main limitation of this study was the short duration of data collection. Therefore, more studies are required to confirm the results obtained in this study by following the patients for at least 24 hours to analyze the CP complications occurred after discharge from the hospital. Another limitation was performance of the study in a single center. It is therefore difficult to generalize the frequency of comorbidities as well as related CP complications. On the other hand, performance of the study by one surgeon, one anesthesiologist, one research resident and one recovery room nurse, prevented individual variations in data collection. In addition, the limited number of patients made the generalization of the study results more difficult.

In conclusion, the results obtained in this study showed that comparison of propofol and midazolam/meperidine sedations during colonoscopy indicated no statistically significant differences with respect to CP complications. A significantly shorter time required for the patient to awaken along with a significantly earlier discharge from the hospital following the colonoscopy were the differences observed in favor of the midazolam/meperidine combination. In addition, although there was no difference between the two sedative approaches with respect to patient satisfaction, the patients in the midazolam/ meperidine sedation group experienced no pain during colonoscopy, whereas the patients sedated with propofol had pain. Therefore, midazolam/meperidine can be preferred to propofol sedation with the benefits of shorter 
hospital discharge time and better analgesic activity.

\section{Acknowledgements}

The authors would like to thank Dr. Serdar Tuncer and the qualified medical writers' team of Edita Writing and Editing Ltd. (www.editawriting.com) for their assistance in drafting the manuscript.

\section{Authors' Contributions}

Study concept and design: Bunyamin Gurbulak, Sinan Uzman, Esin Kabul Gurbulak, Yasar Gokhan Gul, Mehmet Toptas, Sevim Baltali and Osman Anil Savas; analysis and interpretation of data: Bunyamin Gurbulak, Yasar Gokhan Gul and Sevim Baltali; drafting of the manuscript: Bunyamin Gurbulak, Sinan Uzman, Esin Kabul Gurbulak, Yasar Gokhan Gul, Mehmet Toptas, Sevim Baltali and Osman Anil Savas; critical revision of the manuscript for important intellectual content: Bunyamin Gurbulak, Sinan Uzman and Mehmet Toptas; statistical analysis: Sinan Uzman.

\section{Funding/Support}

This study was supported partly by the Endoscopy Center of Arnavutkoy State Hospital , Istanbul, Turkey.

\section{References}

1. Gasparovic S, Rustemovic N, Opacic M, Premuzic M, Korusic A Bozikov J, et al. Clinical analysis of propofol deep sedation for 1,104 patients undergoing gastrointestinal endoscopic procedures: a three year prospective study. World J Gastroenterol. 2006;12(2):327-30.

2. Eberl S, Preckel B, Fockens P, Hollmann MW. Analgesia without sedatives during colonoscopies: worth considering? Tech Coloproctol. 2012;16(4):271-6.

3. Akarsu Ayazoglu T, Polat E, Bolat C, Yasar NF, Duman U, Akbulut S, et al. Comparison of propofol-based sedation regimens administered during colonoscopy. Rev Med Chil. 2013;141(4):477-85.

4. Khajavi M, Emami A, Etezadi F, Safari S, Sharifi A, Shariat Moharari R. Conscious Sedation and Analgesia in Colonoscopy: Ketamine/ Propofol Combination has Superior Patient Satisfaction Versus Fentanyl/Propofol. Anesth Pain Med. 2013;3(1):208-13.

5. Cardin F, Minicuci N, Campigotto F, Andreotti A, Granziaera E, Dona B, et al. Difficult colonoscopies in the propofol era. BMC Surg. 2012;12 Suppl 1:S9.

6. Ekkelenkamp VE, Dowler K, Valori RM, Dunckley P. Patient comfort and quality in colonoscopy. World J Gastroenterol. 2013;19(15):2355-61.

7. Sipe BW, Rex DK, Latinovich D, Overley C, Kinser K, Bratcher L, et al. Propofol versus midazolam/meperidine for outpatient colonoscopy: administration by nurses supervised by endoscopists. Gastrointest Endosc. 2002;55(7):815-25.

8. Chen SC, Rex DK. Review article: registered nurse-administered propofol sedation for endoscopy. Aliment Pharmacol Ther. 2004;19(2):147-55.

9. Triantafillidis JK, Merikas E, Nikolakis D, Papalois AE. Sedation in gastrointestinal endoscopy: current issues. World J Gastroenterol. 2013;19(4):463-81.

10. Rex DK. Review article: moderate sedation for endoscopy: sedation regimens for non-anaesthesiologists. Aliment Pharmacol Ther. 2006;24(2):163-71.
11. Diab FH, King PD, Barthel JS, Marshall JB. Efficacy and safety of combined meperidine and midazolam for EGD sedation compared with midazolam alone. Am J Gastroenterol.1996;91(6):11205 .

12. Ramsay MA, Newman KB, Jacobson RM, Richardson CT, Rogers L, Brown BJ, et al. Sedation levels during propofol administration for outpatient colonoscopies. Proc (Bayl Univ Med Cent). 2014;27(1):12-5.

13. VanNatta ME, Rex DK. Propofol alone titrated to deep sedation versus propofol in combination with opioids and/or benzodiazepines and titrated to moderate sedation for colonoscopy. Am J Gastroenterol. 2006;101(10):2209-17.

14. Pascual MG, Zayas Berbes M, Saez Banos M, Abreu Vazquez Mdel R, Martinez Leyva L. [Propofol versus midazolam and pethidine in the colonoscopy realization]. Acta Gastroenterol Latinoam. 2011;41(3):214-20.

15. Pai MP, Paloucek FP. The origin of the "ideal" body weight equations. Ann Pharmacother. 2000;34(9):1066-9.

16. Chernik DA, Gillings D, Laine H, Hendler J, Silver JM, Davidson $\mathrm{AB}$, et al. Validity and reliability of the Observer's Assessment of Alertness/Sedation Scale: study with intravenous midazolam. $J$ Clin Psychopharmacol. 1990;10(4):244-51.

17. Repici A, Pagano N, Hassan C, Carlino A, Rando G, Strangio G, et al. Balanced propofol sedation administered by nonanesthesiologists: The first Italian experience. World J Gastroenterol. 2011;17(33):3818-23.

18. Ko CW, Riffle S, Michaels L, Morris C, Holub J, Shapiro JA, et al. Serious complications within 30 days of screening and surveillance colonoscopy are uncommon. Clin Gastroenterol Hepatol. 2010;8(2):166-73.

19. Lynn LA, Curry JP. Patterns of unexpected in-hospital deaths: a root cause analysis. Patient Saf Surg. 2011;5(1):3.

20. deRoux SJ, Sgarlato A. Upper and lower gastrointestinal endoscopy mortality: the medical examiner's perspective. Forensic Sci Med Pathol. 2012;8(1):4-12.

21. Sarkar S, Geraghty J, Moore AR, Lal S, Ramesh J, Bodger K, et al. A multicentre study to determine the incidence, demographics, aetiology and outcomes of 6-day emergency readmission following day-case endoscopy. Eur J Gastroenterol Hepatol. 2012;24(12):1438-46.

22. Fanti L, Testoni PA. Sedation and analgesia in gastrointestinal endoscopy: what's new? World J Gastroenterol. 2010;16(20):2451-7.

23. Nayar DS, Guthrie WG, Goodman A, Lee Y, Feuerman M, Scheinberg L, et al. Comparison of propofol deep sedation versus moderate sedation during endosonography. Dig Dis Sci. 2010;55(9):2537-44.

24. Cohen LB, Delegge MH, Aisenberg J, Brill JV, Inadomi JM, Kochman ML, et al. AGA Institute review of endoscopic sedation. Gastroenterology. 2007;133(2):675-701.

25. Liu J, Singh H, White PF. Electroencephalogram bispectral analysis predicts the depth of midazolam-induced sedation. Anesthesiology. 1996;84(1):64-9.

26. Liu J, Singh H, White PF. Electroencephalographic bispectral index correlates with intraoperative recall and depth of propofolinduced sedation. Anesth Analg. 1997;84(1):185-9.

27. Vargo JJ, Zuccaro GJ, Dumot JA, Shermock KM, Morrow JB, Conwell DL, et al. Gastroenterologist-administered propofol versus meperidine and midazolam for advanced upper endoscopy: a prospective, randomized trial. Gastroenterology. 2002;123(1):8-16.

28. Wang D, Wang S, Chen J, Xu Y, Chen C, Long A, et al. Propofol combined with traditional sedative agents versus propofol- alone sedation for gastrointestinal endoscopy: a meta-analysis. Scand J Gastroenterol. 2013;48(1):101-10.

29. Qadeer MA, Vargo JJ, Khandwala F, Lopez R, Zuccaro G. Propofol versus traditional sedative agents for gastrointestinal endoscopy: a meta-analysis. Clin Gastroenterol Hepatol. 2005;3(11):1049-56.

30. Rex DK, Overley CA, Walker J. Registered nurse-administered propofol sedation for upper endoscopy and colonoscopy: Why? When? How? Rev Gastroenterol Disord. 2003;3(2):70-80. 